\title{
Effectiveness of parents and clinicians working together to improve pain management in newborns
}

\author{
Denise Harrison RN PhD, Yiyan Zhou RN MScN, Leanne McArthur RN MN
}

Cite as: CMAJ 2018;190(Suppl 1):S26-S27. doi: 10.1503/cmaj.180338

V enipuncture and heel prick for newborn screening, although essential for early detection of newborn diseases, are painful and repeated procedures that pose a risk of long-term adverse outcomes. ${ }^{1}$ Some parents refuse newborn screening because of concerns about pain in their infants. ${ }^{2,3}$ Evidence-based guidelines recommend that health care professionals support use of breastfeeding, skin-to-skin care, or sucrose or glucose to reduce newborn pain. ${ }^{4,5}$ However, these strategies are underused, and some health care professionals believe that mothers do not wish to be present during painful procedures, ${ }^{6}$ which means that many newborns suffer unnecessarily during painful procedures. Parents of newborns have reported feelings of powerlessness when not supported to comfort their infant. ${ }^{7}$ Despite this, attempts to improve use of strategies to reduce pain have mostly targeted health care professionals, and little research has targeted parents as partners in pain treatment.

We involved parents of infants and clinicians in the design of a trial, funded by the Ontario Child Health Support Unit, to evaluate whether providing mother-baby units within hospitals in Ontario with a video depicting use of pain-reduction strategies, to be shown to parents before newborn screening, increases use of recommended pain treatment during newborn screening compared with delivering usual education targeted to health care professionals only.

Our research team (which includes parents of infants), the Baby-Friendly Initiative, and clinicians and researchers of neonatal pain and knowledge translation, coproduced a five-minute parent-targeted and mediated $^{8}$ video (BSweet2Babies: https:// youtu.be/L43y0H6XEH4). The video portrays babies having blood samples taken while being breastfed, held skin-to-skin and receiving sucrose. The calming effects of these strategies are powerfully portrayed and voice-over in user-friendly language explains how parents can help use these strategies. Although the video is publicly available on YouTube, this channel alone is a passive means of disseminating knowledge, ${ }^{9}$ and the impact of the video on use of the recommended pain-reduction strategies has not, until now, been systematically evaluated.

\section{KEY POINTS}

- High-quality synthesized evidence of effective pain management during painful procedures in newborns exists, but recommended strategies are used infrequently.

- Parents of infants wish to partner with health care professionals to use pain-reduction strategies and comfort their babies during painful procedures.

- Partnerships between parents of infants, health care professionals, researchers and organizational leaders are key to this patient-oriented research project.

- Parents were partners in the research team, contributing in all aspects of the study, and especially informing ways to optimize parents' viewing of the video.

Caring for Babies: A Study of Ontario Maternal-Newborn Hospitals on the Effectiveness of Parent-targeted Education (ONesiE) (ClinicalTrials.gov NCT03099252), funded by OSSU (the Ontario SPOR [Strategy for Patient-Oriented Research] SUPPORT [Support for People and Patient-Oriented Research and Trials] Unit), is a cluster randomized controlled trial (RCT), with active patient engagement (in our case, parent engagement). The objective was to evaluate whether providing mother-baby units within hospitals in Ontario with the BSweet2Babies video before newborn screening increases use of recommended pain treatment during the procedures, compared with mother-baby units with usual education targeted at health care professionals only. A cluster RCT refers to randomization performed at the level of the whole unit, instead of individual patients. The primary outcome was pain management during newborn screening, a data element in the Better Outcomes Registry and Network (BORN) Ontario ${ }^{10}$ routinely collected by all participating mother-baby units.

The power of the study lies in the partnership between parents of infants and health care providers at all stages of this project, from coproducing the BSweet2Babies video, through to planning all aspects of the RCT, including informing ways to optimize parents' viewing of the video. The study 
will facilitate discussion of treatment options in order that families can make informed decisions about their infants' pain care (Box 1).

\section{Box 1: A patient partner's experience}

After my daughter Mary was born, the nurse told me that she needed to have newborn screening and then she took her away from me to another room. I was worried that Mary would have a painful and unhappy experience. I was lying in my bed imagining that she was crying and struggling during her blood test. I wish I could have been there to comfort her and do something for her, but I couldn't. The good thing was that my husband, who knows that sucrose is a pain treatment, went to the room and asked the nurse to give sucrose during the heel lance.

Seeing our babies have these painful procedures, such as blood tests or vaccination, is undoubtedly a bad experience for parents and makes us feel helpless at the same time. Parents need to know ways to relieve babies' pain and how they can get involved in the pain-relief process at the same time. Unfortunately, few parents know any pain-relief methods and much less use them unless health care providers give parents information.

I got to know about pain relief of newborn screening after I was involved in a research project that targets newborn pain management. I helped to translate and voice record the video called "BSweet2Babies" in Chinese. I was impressed by how the babies were so calm and peaceful when they were having blood tests. Of the three ways, I love breastfeeding best, which is simple and easy to [do], so I decided to have a try when my baby had her vaccination. On the vaccination day, I asked the nurse, who didn't mention any of those pain-treatment methods to me, whether I could breastfeed my baby during the injections. The nurse said yes and completed the vaccination while I was breastfeeding Mary. The whole injection process was carried out smoothly and successfully, Mary barely cried, and both the nurse and I were satisfied.

Although I have had my first success, I still feel concerned when I ask health care professionals to help me use these strategies. First, I am afraid they will not support me or decline my request. Not all have knowledge about these pain-management strategies or they may have doubts on the effectiveness, which makes them reluctant to help. Second, I am worried that I will inconvenience them in their work. Some prefer to conduct medical procedures without the presence of parents. In addition, using these strategies might need more time and patience, especially breastfeeding, which should begin a few minutes before painful procedures. It makes me feel uncomfortable if caregivers think I add a burden to their busy work. Third, lacking a comfortable environment to implement these strategies will also be a barrier. For instance, clinics or hospitals where sucrose isn't available or there are no suitable places to hold and breastfeed my baby will weaken my willingness to use these strategies. Once, when Mary had blood collected, I didn't have a private place to breastfeed her and no sucrose was available. I had to give up using these strategies as a result.

I think support from health care professionals will surely give parents more confidence to use pain treatment, and the key to successful implementation of these strategies lies in a close cooperation between parents and health care professionals. This needs not only parents and caregivers to realize the importance of babies' pain management but also to make their endeavours happen. Supporting hospitals to initiate these strategies will definitely be a good way to help benefit more families.
This study evaluating the effectiveness of the BSweet2Babies video when delivered at the level of the organization, on subsequent use of effective pain management during newborn screening has parent, health care professional and organizational leadership partnership at its core. This has potential to benefit newborn infants and their parents.

\section{References}

1. Valeri BO, Holsti L, Linhares MB. Neonatal pain and developmental outcomes in children born preterm: a systematic review. Clin J Pain 2015;31:355-62.

2. Etchegary H, Nicholls SG, Tessier L, et al. Consent for newborn screening: parents' and health-care professionals' experiences of consent in practice. Eur J Hum Genet 2016;24:1530-4.

3. Newborn Screening Ontario. Newborn screening manual: a guide for newborn care providers. Edition 2.1. Ottawa: Children's Hospital of Eastern Ontario; 2018. Available: https://newbornscreening.on.ca/sites/default/files/cho0099_ newborn_screening_manual_2018_-_web.pdf (accessed 2018 Sept. 12).

4. Harrison D, Bueno M, Reszel J. Prevention and management of pain and stress in the neonate. Res Rep Neonatol 2015;5:9-16.

5. Lee GY, Yamada J, Kyololo O, et al. Pediatric clinical practice guidelines for acute procedural pain: a systematic review. Pediatrics 2014;133:500-15.

6. Harrison D, Reszel J, Wilding J, et al. Neuroprotective core measure 5: minimizing stress and pain - neonatal pain management practices during heel lance and venipuncture in Ontario, Canada. Newborn Infant Nurs Rev 2015;15:116-23.

7. Franck LS, Oulton K, Bruce E. Parental involvement in neonatal pain management: an empirical and conceptual update. J Nurs Scholarsh 2012;44:45-54.

8. Stacey D, Hill S. Patient-directed and patient-mediated KT interventions. In: Straus SE, Tetroe J, Graham ID, editors. Knowledge translation in health care. 2nd ed. Oxford (UK): John Wiley \& Sons; 2013.

9. Cooper A. The use of online strategies and social media for research dissemination in education. Education Policy Analysis Archives 2014;22:88.

10. Sprague AE, Dunn SI, Fell DB, et al. Measuring quality in maternal-newborn care: developing a clinical dashboard. J Obstet Gynaecol Can 2013;35:29-38.

More information on this project is available at www.ossu.ca/ IMPACTAwards.

Competing interests: Denise Harrison reports a grant from the Ontario Child Health Support Unit. No other competing interests were declared.

This article was solicited and has been peer reviewed.

Affiliations: Children's Hospital of Eastern Ontario Research Institute (Harrison); parent partner (Zhou), Ottawa, Ont.; Maternal, Newborn, Child and Youth Network (McArthur); London, Ont.

Contributors: All of the authors wrote the commentary, gave final approval of the version to be published, and agreed to be accountable for all aspects of the work.

Funding: The ONesiE study is funded by OSSU (the Ontario SPOR [Strategy for Patient-Oriented Research] SUPPORT [Support for People and Patient-Oriented Research and Trials] Unit).

Acknowledgements: The authors acknowledge Sandra Dunn RN PhD, Marsha Campbell-Yeo RN PhD, Jeremy Grimshaw PhD, Catherine Larocque RN, Stuart Nicholls PhD, Shahirose Premji RN PhD, Jessica Reszel RN MScN, Sonia Semenic RN PhD, Janet Squires RN PhD, Bonnie Stevens RN PhD, Jiale Hu (parent representative), Lucy Gilmore RN MScN, JoAnn Harrold MD, Pat O'Flaherty RN MScN, Marie-Josée Trépanier RN MEd, Kathy Venter RN, and the rest of the ONesiE research team.

Correspondence to: Denise Harrison, denise.harrison@uottawa.ca 